\title{
Estimation of fecal output with an intra-ruminal continuous release marker device
}

\author{
DON C. ADAMS, ROBERT E. SHORT, MICHAEL M. BORMAN, AND MICHAEL D. MACNEIL
}

\begin{abstract}
Efficacy of a continuous release marker device (CRD) containing chromium oxide to estimate fecal output was evaluated in two 12-day grazing trials with beef steers $(n=10$, trial $1 ; n=7$, trial 2$)$. Trial 1 was conducted on mature green irrigated tall wheatgrass (Elytrigia pontica [Podp.] Holub) pasture during September. Trial 2 was conducted on dormant native range during December. Fecal output was determined by total fecal collection (TFC) and the CRD for each steer. Fecal output estimates from the CRD were based on a chromium release rate $(980 \mathrm{mg} /$ day) provided by the manufacturer. Estimates of daily fecal dry matter output (kg) in trial 1 were 2.70 and 2.69 , and in trial 2 were 3.19 and 2.89 from the TFC and CRD, respectively. Differences between TFC and CRD were not significant in trial $1(P=0.59)$ but were significant in trial 2 $(P<0.01)$. When averaged over days and animals, estimates of daily fecal dry matter from CRD were within $1 \%$ of TFC in trial 1 and $10 \%$ of TFC in trial 2. Estimates of daily fecal dry matter from CRD were influenced by sampling day and steer $(P<0.01)$; however, there was no consistent pattern to day or animal variation. Multiple days and animals are required for both TFC and CRD. We conclude that CRD provides an acceptable estimate of daily fecal output. However, to improve accuracy, TFC can be used on a subsample of animals as a double sampling technique to adjust estimates derived from CRD.
\end{abstract}

Key Words: beef cattle, pasture, rangeland, forage intake, chromic oxide

Forage intake by grazing animals has generally been determined by dividing fecal output by forage indigestibility (Schneider and Flatt 1975). Fecal output has been estimated by total collection and by various external indicator techniques (Raleigh et al. 1980, Krysl et al. 1985, Cochran et al. 1987). Chromic oxide has been used widely as an external indicator for fecal output (Raleigh et al. 1980). Daily dosing with chromic oxide is a useful external indicator technique, but estimates from this procedure have been plagued with high and low recoveries and erratic marker excretion patterns (Raleigh et al. 1980, Galyean et al. 1986). An intraruminal controlled release device (CRD) for chromic oxide has been developed for estimating fecal output in grazing animals (Ellis et al. 1981, Ellis et al. 1982; Harrison et al. 1981; Laby et al. 1984). The CRD greatly reduced the within-day coefficient of variation for fecal concentrations of chromium in sheep and cattle when compared with dosing chromic oxide in a gelatin capsule twice daily.

Further research is warranted to determine the accuracy and precision of CRD estimates of fecal output. Additional work is needed to determine number of fecal samples and animals required for specific field objectives. Our objectives were to evaluate the CRD with different forages and environmental conditions and to

\footnotetext{
Authors are with the University of Nebraska-Lincoln West Central Research and Authors are with the University of Nebraska-Lincoln West Central Research and
Extension Center, North Platte, Nebr. 69101 (Adams, formerly with USDA-ARS) and USDA Agriculture Research Service at Ft. Keogh Livestock and Range Research Laboratory, Rt. I Box 2021, Miles City, Montana 59301 (Short, Borman, and MacNeil).

This paper is a contribution from the USDA, Agriculture Research Service and Montana Agriculture Experiment Station, Miles City, Montana. Mention of a trade name or product does not constitute a recommendation or endorsement for use by the USDA.

Publication has been approved by the Director of the Montana Agr. Exp. Sta.," Journal Ser. J-2451.

Manuscript accepted 18 June 1990.
}

examine fecal sampling procedures. Our hypothesis was that with appropriate sampling procedures, the CRD would provide an estimate of fecal output equal to that obtained by total collections.

\section{Materials and Methods}

Two independent trials were conducted with beef steers using the CRD developed for cattle ${ }^{1}$ and total fecal collection (TFC). Trial 1 was conducted from 19 September (day 1) to 8 October 1988, in a 25-ha irrigated tall wheatgrass (Elytrigia pontica [Podp.] Holub) pasture, with 10 beef steers (average live weight $=330 \mathrm{~kg}$ ). Trial 2 was conducted from 22 November (day 1) to 10 December 1988, in a 73-ha native range pasture with 8 beef steers (average light weight $=290 \mathrm{~kg}$ ). Principal forage species in the native range pasture were western wheatgrass (Pascopyrum smithii [Rydb.] Love), blue grama (Bouteloua gracilis [H.B.K.] Lag. ex Griffiths), buffalo grass (Buchloe dactyloides [Nutt.] Engelm.), needle-and-thread grass (Stipa comata Trin. and Rupr.), green needlegrass (Stipa viridula Trin.), and threadleaf sedge (Carex filifolia Nutt.). Principal shrubs were big sagebrush (Artemisa tridentata Nutt. ssp wyomingensis Beetle and Young), silver sagebrush (Artemisia cana Pursh), and greasewood (Sarcobatus vermiculatus [Hook.] Emory.).

On day 1 of each trial, steers were given a CRD orally. The release rate of the CRD, determined from grazing trials by the manufacturer, was $1,433 \mathrm{mg}$ chromic oxide/day or $980 \mathrm{mg} \mathrm{Cr} /$ day. Manufacturer specifications state that 6 days after dosing the capsule, the mass of $\mathrm{Cr}_{2} \mathrm{O}_{3}$ being released by the capsule is equal to that being excreted in the feces. This steady state exists from day 6 to day 20 and is the recommended period for fecal sampling. On days 6 through 18 each steer was fit with a fecal bag and TFC were made. Feces in bags were weighed, mixed, subsampled (B), and emptied beginning at 0800 each day during the collection period. At the same time, a rectal grab sample of feces (150 to 300 grams) was collected (R). Chromium determination in the fecal sample obtained from TFC (sample B) has been used to correct for high and low chromium recoveries (Kartchner 1980). Our rationale for collecting the B sample was to determine if a recovery technique of this type would be of value with the CRD.

Five esophageally fistulated steers (average light weight $=\mathbf{5 5 0}$ $\mathrm{kg}$ ) were grazed with the steers given the CRD during each trial. On days 9 and 15 of each trial, after an overnight fast, forage samples were collected from the fistula of each steer during a 30- to 45minute grazing period. Fistula forage samples were composited across both collection days and steers for each trial. Fecal and fistula samples were dried at $45^{\circ} \mathrm{C}$ and ground in a Wiley mill to pass a 1-mm screen. Fistula samples were analyzed for dry matter and Kjeldahl nitrogen by standard procedures (AOAC 1984) and for neutral detergent fiber, acid detergent fiber, and acid detergent lignin according to Goering and Van Soest (1970). Results of chemical composition analyses for forages are presented in Table 1. Fecal samples ( $R$ and $B$ ) were prepared for chromium analysis as described by Williams et al. (1962) and chromium concentrations were determined by atomic absorption spectroscopy.

Method (TFC, B and R), steer, and day effects on fecal output estimates were evaluated with a split-plot analysis of variance.

Captec chrome manufactured by Captec Pty. Ltd., Australia, distributed internationally by Nufarm Limited, Manu Strect, Otahunu, P.O. Box 22-407, Auckland 6, New Zealand. 
Table 1. Crude protein (CP), neutral detergent fiber (NDF), acid detergent fiber (ADF), and acid detergent lignin (ADL) percentages of forage samples collected from esophageally-fistulated steers during 2 trials.

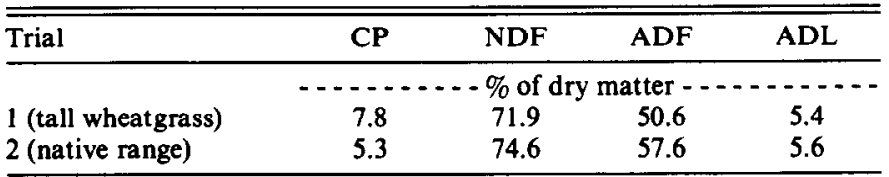

Effects of steer and day were random. Based on the expected mean squares (Table 2), steer effects were tested with the steer $\times$ method mean square as error; method effects were tested with a synthesized mean squares with the expectation $\sigma_{\mathrm{e}}^{2}+\mathrm{k}_{1} \sigma_{\mathrm{m} * \mathrm{~d}}^{2}+12 \sigma^{2}{ }_{\mathrm{s} * \mathrm{~m}}$, where $\mathrm{k}=$ 10 in trial 1 and $k=7$ in trial 2; day effects were tested with the day $X$ method mean square; and steer $X$ method effects and day $X$ method effects were tested with the residual error mean square. Approximate degrees of freedom for the synthesized mean square are 21 in trial 1 and 20 in trial 2 . A formula is presented using estimated variance to jointly minimize the cost of experiments with the CRD and the experimental error variance.

\section{Results and Discussion}

During trial 2, the chromium and concentration in the feces rapidly declined for 1 steer during the collection period. Either the bolus failed or it was regurgitated by the steer. Data from this steer was deleted from the statistical analysis. Following completion of these 2 grazing trials, we found several of the CRD in a drylot where the steers were housed. Hence, cattle can regurgitate the CRD.

Method and steer effects and method $X$ day interaction were significant $(P<0.01)$ in both trials. Method $X$ day interaction in trial 1 appears to be a result of $B$ deviating from both TFC and $R$ during several days mid-trial (Fig. 1). Individual steer fecal dry matter output estimates from the CRD deviated both positively and negatively from TFC (Fig. 2). During trial 2, both B and R underestimated fecal dry matter compared with TFC for the first several days (Fig. 3) and for several steers (Fig. 4). Steer and day effects indicate that multiple days and animals are required to obtain reliable estimates of fecal output by any of the 3 methods.

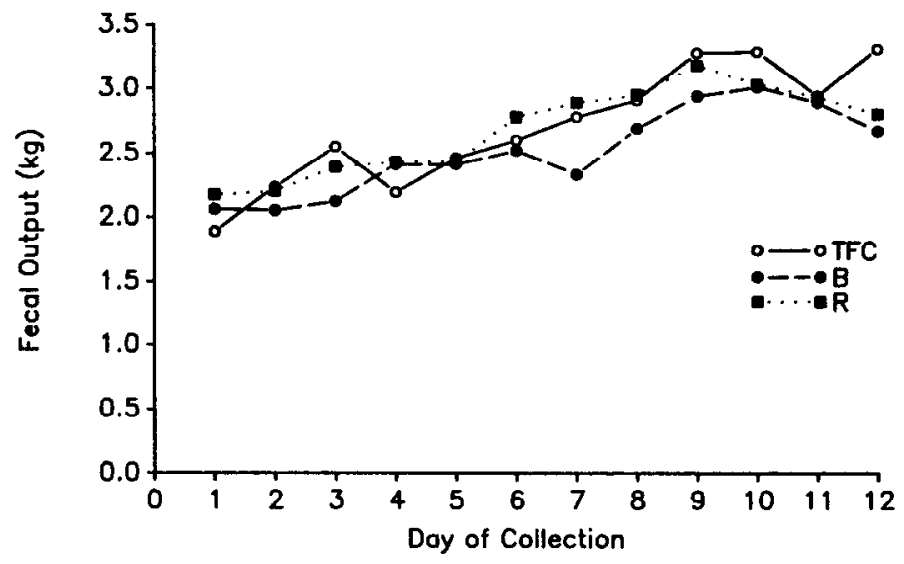

Fig. 1. Daily estimates of mean fecal production (kg) by 10 steers for total fecal collection (TFC), chromium concentration from sample obtained from the fecal bag (B), and by chromium concentration of fecal sample obtained from rectum of steers (R), Trial 1.

Results from a study reported by Ellis et al. (1982) may provide partial explanation for the steer effect. Ellis et al. (1982) found that CRD retrieved through a rumen fistula had greater release rates than those undisturbed in intact cattle. They concluded that the difference in release rate between CRD in fistulated and intact animals was caused by disturbance of the releasing surface of the CRD. Therefore, variation in release of the CRD between animals in our study might have resulted from variable effects of forage movement within the rumen on the CRD releasing surface between animals. Further, inconsistencies in flow of the chromic oxide from the rumen and through other portions of the gastrointestinal tract might have occurred because the chromic oxide was not bound to plant fractions. Ellis et al. (1982) found that after day 2 in the rumen the release rate of chromium from the CRD was linear and concluded that variation of release rate between animals was mostly attributed to chromium measurement techniques. Other research (Laby et al. 1984) with the CRD has shown that the release rate of the CRD was independent of the diet consumed, age of animal and whether the animal was penned or grazing. Trials

Table 2. Analysis of variance tables, trials 1 and 2.

\begin{tabular}{|c|c|c|c|}
\hline Source & Degrees of freedom & Sum of squares & Expected mean squares \\
\hline $\begin{array}{l}\text { (Trial 1) } \\
\text { Model } \\
\text { Steer }{ }^{1} \\
\text { Method }^{2} \\
\text { Steer } \times \text { Method }^{3}\end{array}$ & $\begin{array}{r}62 \\
9 \\
2 \\
18\end{array}$ & $\begin{array}{r}86.56 \\
32.89 \\
2.65 \\
1.76\end{array}$ & 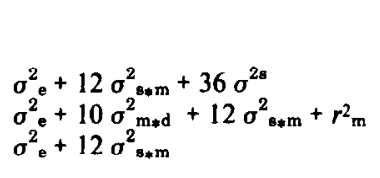 \\
\hline $\begin{array}{l}\text { Day }^{4} \\
\text { Method } \times \text { Day }^{3}\end{array}$ & $\begin{array}{l}11 \\
22\end{array}$ & $\begin{array}{r}44.26 \\
4.99\end{array}$ & $\begin{array}{l}\sigma_{\mathrm{e}}^{2}+10 \sigma_{\mathrm{m}+\mathrm{d}}^{2}+30 \sigma_{\mathrm{d}}^{2} \\
\sigma_{\mathrm{e}}^{2}+10 \sigma_{\mathrm{m} * \mathrm{~d}}^{2}\end{array}$ \\
\hline Error & 297 & 23.71 & $\sigma_{\mathrm{e}}^{2}$ \\
\hline $\begin{array}{l}\text { (Trial 2) } \\
\text { Model }\end{array}$ & 53 & 45.63 & \\
\hline $\begin{array}{l}\text { Steer }{ }^{1} \\
\text { Method }^{2} \\
\text { Steer } \times \text { Method }^{3}\end{array}$ & $\begin{array}{r}6 \\
2 \\
12\end{array}$ & $\begin{array}{r}20.71 \\
4.46 \\
3.62\end{array}$ & $\begin{array}{l}\sigma^{2}{ }_{\mathrm{e}}+12 \sigma_{{ }^{3 * \mathrm{~m}}}^{2}+36 \sigma^{2 \mathrm{~s}} \\
\sigma_{\mathrm{e}}^{2}+7 \sigma_{\mathrm{m}+\mathrm{d}}^{2}+12 \sigma_{8 * \mathrm{~m}}+\tau_{\mathrm{m}}^{2} \\
\sigma_{\mathrm{e}}^{2}+12 \sigma_{\mathrm{s*m}}^{2}\end{array}$ \\
\hline $\begin{array}{l}\text { Day }^{4} \\
\text { Method } \times \text { Day }^{3}\end{array}$ & $\begin{array}{l}11 \\
22\end{array}$ & $\begin{array}{r}10.87 \\
5.95\end{array}$ & $\begin{array}{l}\sigma_{\mathrm{e}}^{2}+10 \sigma_{\mathrm{m} * \mathrm{~d}}^{2}+21 \sigma_{\mathrm{d}}^{2} \\
\sigma_{\mathrm{e}}^{2}+10 \sigma_{\mathrm{m} * \mathrm{~d}}^{2}\end{array}$ \\
\hline Error & 198 & 23.47 & $\sigma_{\mathrm{e}}^{2}$ \\
\hline
\end{tabular}

'Steer main effect tested with steer $\times$ method expected mean square as error.

${ }_{2}^{2}$ Method main effect tested with the following synthesized expected mean square as error: $\sigma_{\mathrm{e}^{2}}^{2}+\mathrm{k}_{\mathrm{i}} \sigma_{\mathrm{m} * \mathrm{~d}}^{2}+12 \sigma_{\mathrm{s}}^{2} \mathrm{~m}$, where $\mathrm{k}=10$ in trial 1 and $\mathrm{k}=7$ in trial 2 .

${ }^{3}$ Steer $\times$ method and method $X$ day interaction terms tested with residual error mean square.

${ }^{4}$ Day main effect tested with method $X$ dav interaction expected mean square as error. 


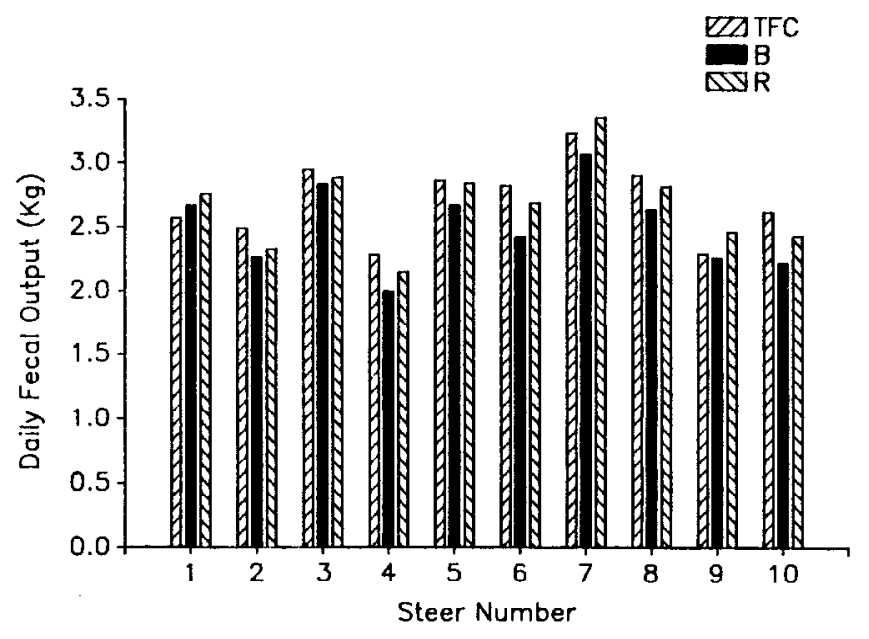

Fig. 2. Estimates of mean daily fecal production (kg) by each steer over 12 days of collection by total fecal collection (TFC), by chromium concentration from sample obtained from fecal bag (B), and by chromium concentration of fecal sample obtained from rectum of steers $(R)$, Trial 1.

utilizing forage and concentrate diets in various forms (i.e., pelleted or unpelleted) showed inconsistency of CRD release rate between diets (Burns et al. 1989, Pond et al. 1990). Because the manufacturer release rate was determined in grazing animals, the extent to which concentrate or pelleted diets can be related to the grazing animal is not clear. Variation of fecal production estimates based on chromium concentrations in B and $R$ relative to TFC may have been a function of differences from manufacturer specifications in payout of $\mathrm{Cr}_{2} \mathrm{O}_{3}$ from boluses and/or subsampling errors affecting chromium recovery.

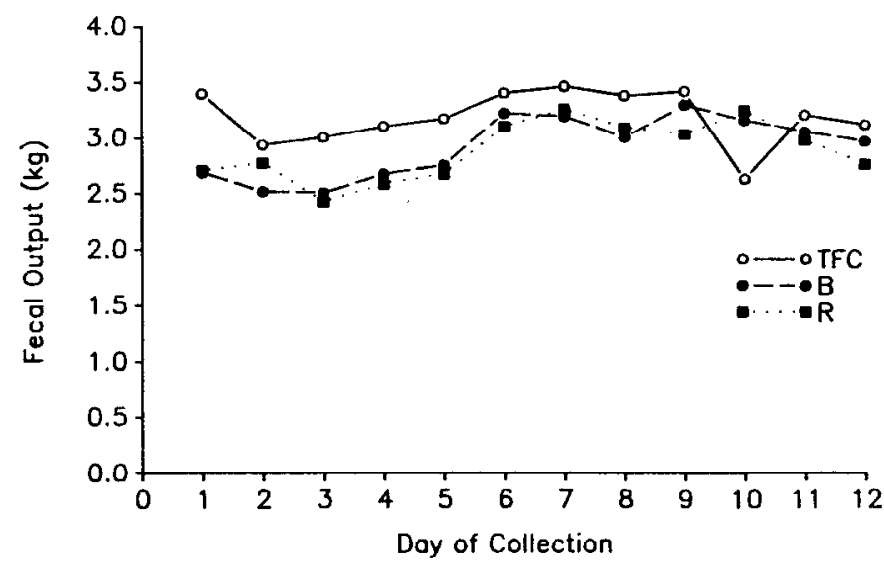

Fig. 3. Daily estimates of mean fecal production (kg) by 7 steers for each day by total fecal collection (TFC), chromium concentration from sample obtained from the fecal bag (B), and by chromium concentration of fecal sample obtained from the rectum of steers $(R)$, Trial 2.

Trial 1 fecal output estimates (kg/day) were 2.70 (TFC), 2.51 (B), and $2.68(\mathrm{R})$. Method differences in trial 1 were significant between $B$ and both TFC and R (Table 3). Fecal output estimates $(\mathrm{kg} /$ day) by TFC and $\mathrm{R}$ were similar. Trial 2 fecal production estimates (kg/day) were 3.19 (TFC), 2.93 (B), and 2.89 (R). During trial 2, method differences were significant between TFC and both $B$ and $R$ (Table 3). Fecal output estimates by $B$ and $R$ were similar. When averaged across both steers and days, fecal output estimates by CRD were within $10 \%$ of TFC in both trials (Table 3). Recovery of chromium from the CRD could be checked and an adjustment made on fecal output by making TFC on a subset of experimental
Table 3. Comparison of total fecal collection (TFC) and chromium determinations on fecal samples obtained from fecal bag (B) and rectally (R) as methods for estimating daily fecal dry matter output (kg/steer).

\begin{tabular}{lccccc}
\hline \hline & \multicolumn{2}{c}{ Trial 1 } & & \multicolumn{2}{c}{ Trial 2 } \\
\cline { 2 - 3 } \cline { 5 - 6 } Comparison & $\begin{array}{c}\text { Percent } \\
\text { differencel }\end{array}$ & $\mathbf{P}^{2}$ & & $\begin{array}{c}\text { Percent } \\
\text { difference }\end{array}$ & $\mathbf{P}$ \\
\hline TFC - B & 8 & 0.01 & & 9 & 0.01 \\
TFC - R & 1 & 0.81 & & 10 & 0.01 \\
B - R & -7 & 0.01 & & 2 & 0.65 \\
\hline
\end{tabular}

' Percent difference between compared techniques used to estimate daily fecal production averaged over all days and all steers within each trial.

2Probability level at which compared techniques provided significantly different estimates of daily fecal output.

animals. A correction factor would be obtained by dividing the mean fecal output estimated from $R$ by the mean fecal output estimated by TFC for the subset. The fecal output estimated from $\mathbf{R}$ for each animal in the experiment would be multiplied by the correction factor. A correction based on chromium concentration from a fecal sample taken from the fecal bag (method B) is not needed.

Deviations from the 12-day mean by individual days and all combinations of days were evaluated for trial 1 to determine if some combination of fewer days could be used to accurately estimate the 12-day mean of estimated fecal production (data not shown). Results indicated that the CRD will accurately estimate fecal production for any given day. These analyses did not reveal criteria for selection of a subset of days to estimate fecal output for the entire 12-day period. If an estimate of fecal production is desired for a period (e.g., 12 days), accuracy for the period will be greatest if all 12 days are sampled. The number of days required depends on the accuracy desired (i.e., more days sampled, within the 6 to 20-day postdose period recommended by the manufacturer, increases accuracy of the estimate for the period). Six to 7-day fecal collection trials have been successfully used to estimate fecal production in previous studies (Adams 1985, Adams et al. 1987, Cochran et al. 1987). The 14-day sampling period provided by the CRD allows researchers to sample all or some subsample of days within that period. Since intensive handling of animals has been shown to affect grazing activity (Cochran et al. 1987), collecting samples on alternate days may reduce effects due to handling and still allow estimates of fecal production over 6 to 7 days within a trial.



Fig. 4. Estimates of mean daily fecal production (kg) by each steer over 12 days of collection by total fecal collection (TFC), by chromium concentration from sample obtained from fecal bag (B), and by chromium concentration of fecal sample obtained from rectum of steers (R), Trial 2. 


\section{Animal and Day Requirement Calculations}

The following procedure (Gill 1978) can be used to calculate the combination of number of animals and number of days required in a trial to minimize experimental error given a fixed budget. The variance of a treatment is $\sigma_{x}^{2}=\left(\sigma_{e}^{2}+d \sigma_{s}^{2}\right) / d s$, where $d=$ number of days and $s=$ number of steers. Let the cost per day be $c_{1}$ and the cost per steer be $c_{2}$. The value of $d$ that jointly minimizes the cost of the experiment and $\sigma_{\mathrm{x}}^{2}$ is $\mathrm{d}^{\prime}=\sqrt{\left[\left(\mathrm{c}_{2} / \mathrm{c}_{1}\right)\left(\sigma_{\mathrm{e}} / \sigma_{\mathrm{B}}{ }^{2}\right] \text {. If the allowable cost }\right.}$ of the experiment if fixed at $\$ /$ treatment (trt), then $\$=c_{1} s d^{\prime}+c_{2} s$ and $s^{\prime}=\$ /\left(c_{1} d^{\prime}+c_{2}\right)$

For example, pooled estimates of the between steer and error variance components obtained from trials 1 and 2 are: $\sigma_{s}^{2}=0.0932$ and $\sigma_{e}{ }_{e}=0.0954$. If lab analysis, labor, etc. for each day's sample costs $\left(c_{1}\right)=\$ 15$ and each steer costs $\left(c_{2}\right)=\$ 300$ (costs for this example are hypothetical), given our estimate of $\sigma^{2}$ and $\sigma_{n}^{2}$, we have

$$
d^{\prime}=\sqrt{[(300 / 15)(0.0954 / 0.0932)]=4.42}
$$

and if $\$ 3000 /$ trt is available, then

$$
s^{\prime}=3000 /[(15 * 4.42)+300]=8.19
$$

Therefore, fecal samples collected from 8 steers on 4 days would minimize experimental error within the specified resources.

Calculations to determine numbers of animals and days required to estimate fecal output within a defined level of confidence can also be made with information derived from the analysis of variance table (Table 2).

\section{Conclusions}

CRD appears to be a reliable method for obtaining estimates of fecal dry matter output in grazing trials. In this study, estimates of fecal output from (R) were within 10\% of estimates from TFC. However, TFC could be used on a subset of animals as a double sampling technique to correct for possible CRD payout differences from manufacturer specifications and/or subsampling influences on chromium recovery. Further studies with grazing animals are needed to evaluate the influences of forage quality and class and condition of animal on estimates of fecal output by CRD. Both TFC and CRD require multiple sample days and animals. Number of days required will depend on 2 factors: (1) the number of days for which an estimate of fecal production is desired (up to 14 days, manufacturer specifications), and (2) the degree of accuracy with which fecal production is to be estimated. Accuracy improves with an increasing number of days sampled within the time period for which an estimate of fecal output is desired. Sampling alternate days would reduce the influence of handling on animal behavior and still allow 6 to 7 estimates of fecal production within a trial.

\section{Literature Cited}

Adams, D.C. 1985. Effect of time of supplementation on performance, forage intake and grazing behavior of yearling beef steers grazing Russian wild ryegrass in the fall. J. Anim. Sci. 61:1037-1042.

Adams, D.C., R.C. Cochran, and P.o. Currie. 1987. Forage maturity effects on rumen fermentation, fluid flow, and intake in grazing steers. $J$. Range Manage. 40:404-408.

AOAC, 1984. Official Methods of Analysis (14th Ed.) Association of Official Analytical Chemists. Washington, DC.

Burns, J.C., K.R. Pond, J.M. Luginbuhl, D.S. Fisher. 1989. Evaluation of the captec controlled release device for fecal output estimation. 20th Biennial Conference on Rumen Function. Chicago, Ill. Abstr. 18

Cochran, R.C., D.C. Adams, M.L. Galyean, and J.D. Wallace. 1987. Examination of methods for estimating rate of passage in grazing steers. J. Range Manage. 40:105-108.

Ellis, K.J., R.H. Laby, and R.G. Burns. 1981. Continuous controlled release administration of chromic oxide to sheep. Proc. Nutr. Soc. Australia. 6:145.

Ellis, K.J., R.H. Laby, P. Costigan, K. Zirkler, and P.G. Choice. 1982. Continuous administration of chromic oxide to grazing cattle. Proc. Nutr. Soc. Australia. 7:177

Galyean, M.L., L.J. Krysl, and R.E. Estell. 1986. Marker-based approaches for estimation of fecal output and digestibility in ruminants. In: Feed Intake of Beef Cattle: Symposium, F.N. Owens (ed.) Oklahoma State Univ., Stillwater, MP 121:96-113.

Gill, J.L. 1978. Design and analysis of experiments in the animal and medical sciences. Vol. 1. lowa State University Press, Ames. p. 199-201.

Goering, H.K., and P.J. Van Soest. 1970. Forage and fiber analyses. ARS, USDA Agr. Handb. 379.

Harrison, F.A., R.H. Laby, and J.L. Mangan. 1981. A slow-release marker capsule for studies of digestion in the sheep. J. Physiology. 319:1p.

Kartchner, R.J. 1980. Effects of protein and energy supplementation of cows grazing native winter range forage on intake and digestibility. $J$. Anim. Sci. 51:432-438.

Krysl, L.J., F.T. McCollum, and M.L. Galyean. 1985. Estimation of fecal output and particulate passage rate with a pulse does of ytterbium labeled forage. J. Range Manage. 38:180-182.

Laby, R.H., C.A. Graham, S.R. Edwards, and B. Kautzner. 1984. A controlled release intraruminal device for the administration of fecal dry-matter markers to the grazing ruminant. Can. J. Anim. Sci. 64 (suppl.):337-338.

Pond, K.R., J.M. Luginbuhl, J.C. Burns, D.S. Fisher, and T.G. Goodwin. 1990. Estimating fecal output of cattle with the captec controlled release capsule and by the single dose ytterbium marker method. American Soc. Anim. Sci. Southern Section. Abstr. 117.

Raleigh, R.J., R.J. Kartchner, and L.R. Rittenhouse. 1980. Chromic oxide in range nutrition studies. Oregon State Univ., Corvallis. Bull. 641.

Schneider, B.H., and W.P. Flatt. 1975. The evaluation of feeds through digestibility experiments. Univ. of Georgia Press, Athens. p. 178-179.

Williams, C.H., D.J. David, and O. lisman. 1962. The determination of chromic oxide in faeces samples by atomic absorption spectrophotometry. J. Agr. Sci. (Camb.) 59:381-385. 